\title{
Conceptualization of an Alternate Mechanism of Moulded Case Circuit Breaker (MCCB) To Reduce Reset Force
}

Saad A. Shaikh ${ }^{1}$, Saad Shaikh ${ }^{2}$

${ }^{1}$ Assistant Professor, Department of Mechanical Engineering, Anjuman-I-Islam Kalsekar Technical

Campus School of Engineering, Panvel, Mumbai University, Maharashtra(India).

${ }^{2}$ B.E.Mech.(Student), Anjuman-I-Islam Kalsekar Technical Campus School of Engineering, Panvel,

Mumbai University, Maharashtra(India).

\section{Abstract}

An electro-mechanical device that is used to protect an electric circuit from damage caused by overload or short circuit is used widely and it is known as Moulded Case Circuit Breaker (MCCB). This paper deals with the conceptualization of an alternate model for the mechanism used in MCCB. Forces in the mechanism are directly related to friction between the components so, if we manage to reduce the coefficient of friction between the components without affecting its function there is a scope of reducing reset forces of themechanism. The new model of sub-assembly in MCCB mechanism has a roller contact between the surfaces instead of sliding contact as compared to the existing mechanism. After calculating forces between all the components using rolling friction, it can be concluded that reset force is expected to reduce by 3-4 kilograms.

Keywords: Moulded Case Circuit Breaker, electro-mechanical, co-efficient of friction, rolling friction

\section{Introduction}

This paper deals with the development of a mechanism that shall replace the existing mechanism. The motivation behind the development is that we need to reduce the reset force for that first we shall find out all the causes and then work on it one by one. Out of all the causes, Friction is the major contributor. If we reduce the friction between the components by some alternate means without affecting the performance, quality, working and many other factors like ease of assembly, ease of maintenance, etc. then the reset force of the MCCB is expected toreduce. Friction arises at the real contact area of two contacting bodies [14]. Friction is the forceresisting the relative motion of solid surfaces, fluid layers, and material elements sliding against each other. There are several types of friction out of which two are considered in the research. They are (i) Sliding friction and (ii) Rolling friction. Friction can be less with grease than with oil [15]. Rolling connexions are commonly found in industries, such as railway systems [1, 2].Rolling bodies often shift under rollingcondition because of the geometry track, the traction force or the braking force, such as a train transit through curve track, and brakes on track [5]. Since body rollingsliding is a complicated movement, there are so far few analytical expressions for it that can be used to describe the friction behaviors of rollingsliding bodies [5]. When a ball rolls over a plate, there area of contact includesa small stick region [3]. This are of the stick region will become smaller with increased traction force or the brake force [5]. In this method, the coefficient of friction steadily increases with the increase in tangential force $[3,4]$. When the tangential force reaches its height the region of stick disappears in the area of contact and ball just slides over plate 
[5].

Some studies predict better wear behavior, based on Archard's wear models, whilst others have a good performance in prediction of rolling contact fatigue [6]. The sliding friction coefficient $\mu$ s has a maximum valueof 0.11 , under dry contact conditions, while this value decreases in presence of a lubricant film[7].Just two symmetrical lines of pure rolling occur in the contact ellipse at the touch between a ball and the rolling track in a thrust ball bearing, in the absence of additional spin due to zero ball-race contact angleand in the absence of the gyroscopic motions [8]. Positive and negative sliding speeds can be described elsewhere, since the touch ellipse is curved in space [9].The wear rate increased with the sliding speed while load produced a mixed influence [10].

Selection of the most suitable bearing type for a particular duty can pose a difficult problem due to the wide range of bearings available [11]. To assist the designer these notes, describe the more-frequently-used types of ball and roller bearings and their components and refer to some of their uses and limitations [11]. Many examples of balls and rollers being used to reduce friction were employed during the middle ages, and in the early sixteenth century cast-iron balls replaced those of stone for offensive purposes for placing under gun carriages to render their movement easy [12]. A limited amount of reduction was found in the coefficient of friction due to the use of boundary lubricant from that in the dry testing [13].

The remainder of the paper is organized in the following manner: Section 2 describes the problem. Section 3 is devoted to find various causes and its actions. Section 4 deals with the existing mechanism. Further mechanisms changes are incorporated in Section 5. Section 6 concludes theresearch.

\section{ProblemDefinition}

The mechanism of MCCB comprises of a Knob (1), Fork (2), latch (3), latch bracket (4), upper link (5), lower link (6), upper contact (7), lower contact (8), mechanism plate (9) and spring with a rivet inserted between floating pin and fork (10). Component (10) is not shown in the figure.

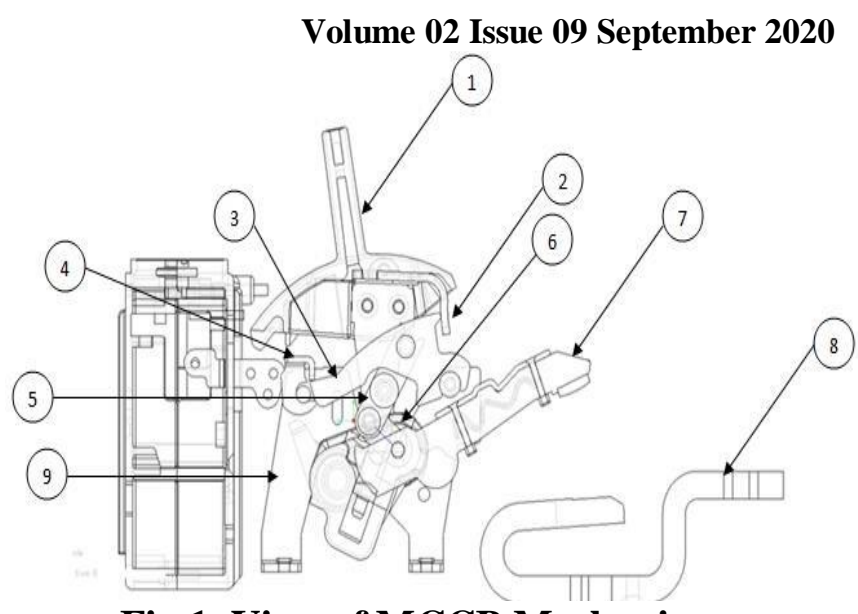

Fig.1. View of MCCB Mechanism

Mechanism being the heart of MCCB, therefore it needs to operate efficiently. Any failure in it may lead to total failure of MCCB. Mechanisms main function is to operate the MCCB with the help of various components as shown in figure 1. There is a contact between latch and fork, which is of sliding type. If we change the contact from sliding to rolling, then frictional force will be reduced in turn our goal of reducing reset force will be accomplished.

The mechanism is supposed to elongate the spring and efficiently transfer the energy to close the contacts. Contacts should be close with a wide range of force. For the elongation of mechanism springs an external force is required that is to be transmitted from Knob to the contacts. The force requires to reset the MCCB should be as minimum as possible so that resetting is smooth and with less effort. There are many problems for high reset force.One of the major and most important reasons for high reset force is friction. Fig. 2 shows all the causes of high reset force. If friction between mating parts is reduced by some means reset force will drastically reduce and then operation of the MCCB will become smooth and easy.This motivated us to develop a mechanismby using rolling contact instead of sliding contact.

\section{Finding out causes and working on major contributor}

There are multiple views about the root cause of the problem when using a collaborative approach to problem solving. The cause and effect diagram, usually called a fishbone is the one way of capturing these diverse ideas and encourage the teams brainstorming about root causes. The fishbone can help visually illustrate the many 
www.rspsciencehub.com

possible reasons for a particular issue or effect. It is especially useful in a group setting and in circumstances where there is little quantitative data available for analysis.Fig. 2 shows the cause and effect diagram drawn from the observed problems. From the given figure, it can be concluded that problems such Mechanism spring, contact between latch and fork, Friction between various components are some of the major consequences of high reset force.

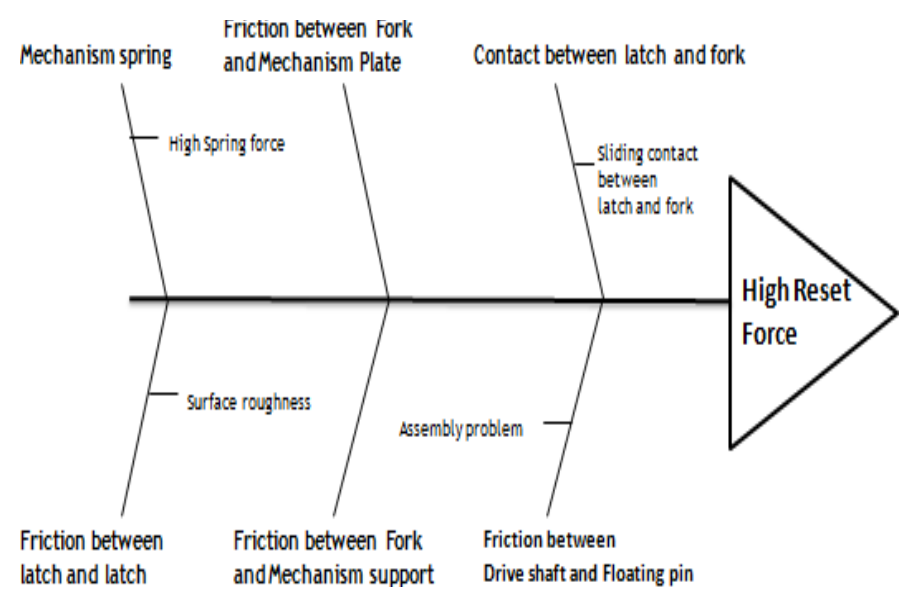

Fig.2. Cause Effect Diagram

As seen from fig.2 friction is the major contributor in high reset force. Friction is to be eliminated or reduced so as to reduce the reset force.

The rolling of surfaces is much easier than the sliding. Rolling friction is the resistance to motion that occurs when a surface is rolling over a different surface.Typically, the term rolling friction is restricted to bodies of nearly perfect (continuous) forms with very mild roughness on the surface. The coefficient of rolling friction between a cylindrical or spherical body against itself or a flat body with hard materialsusually is in the range of $5 \times 10^{\wedge}-3$ to $10^{\wedge}-3$. In contrast the sliding friction coefficient of dry bodies usually varies from 0.1 to often much higher than1. Any relative motion can be viewed as a mixture of rolling, sliding and spinning, during rolling of two surfaces relative to each other.Consider two nonconforming bodies which are in contact at a single point O. Figure 3, Sliding (or slip) is the relative linear velocity between the two surfaces at the point of contactO in the tangent plane, rolling is the relative angular velocity between the two bodies around an axis lying in the tangent plane and spin is the relative angular velocity between the two surfaces around the general
Volume 02 Issue 09 September 2020 normal through 0 . We describe free rolling as a rolling motion in which there can be no tangential (friction) process or sliding (slip). Tractive rolling is the rolling motion in which the friction force or slip is nonzero; strong tangential forces are transmitted in the in the driving wheels of a train on the tracks or traction drives. The simplest type of free rolling occurs between two bodies that aregeometrically similar with the same elastic properties, and experience little deformation in the contact area. In tractive rolling the friction force in the contact region where $\mu$ is coefficient of the sliding frictionandWisthenormalloadmust be less than or equal to $\mu \mathrm{W}$. When friction force exceed $s \mu \mathrm{W}$, there is local sliding (microslip) or gross sliding (throughout the contact).



Fig.3. In contact with two non-conforming bodies 1 and 2 at point $O$

\section{Existing MCCBmechanism}

Fig. 4 shows the existing latch as a part of mechanism which is a subassembly in the MCCB. Mechanism is considered to be the heard of MCCB. The main function of mechanism is to vary the position of upper contact that is to reset, on and off the MCCB.

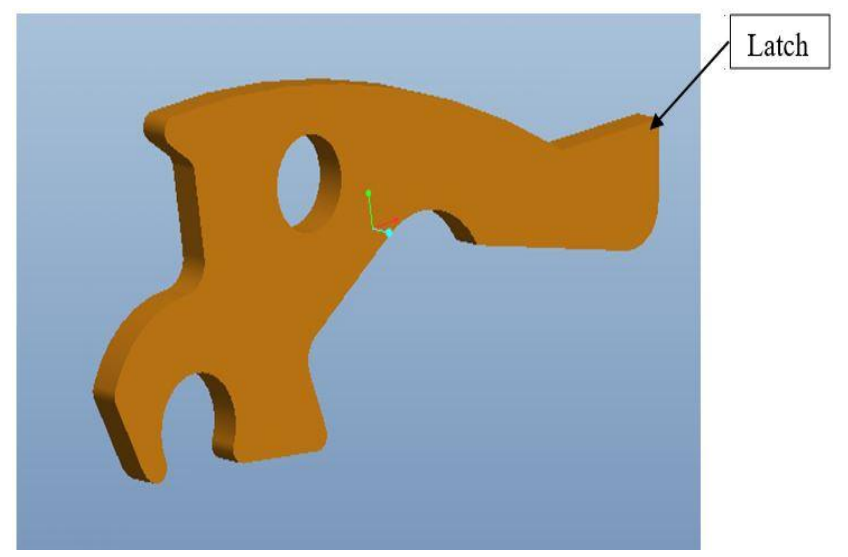

Fig.4. Existing Latch 


\section{Proposed model for MCCBmechanism}

An alternate model was conceptualized to reduce the frictional force as a result of which reset force will be reduced.

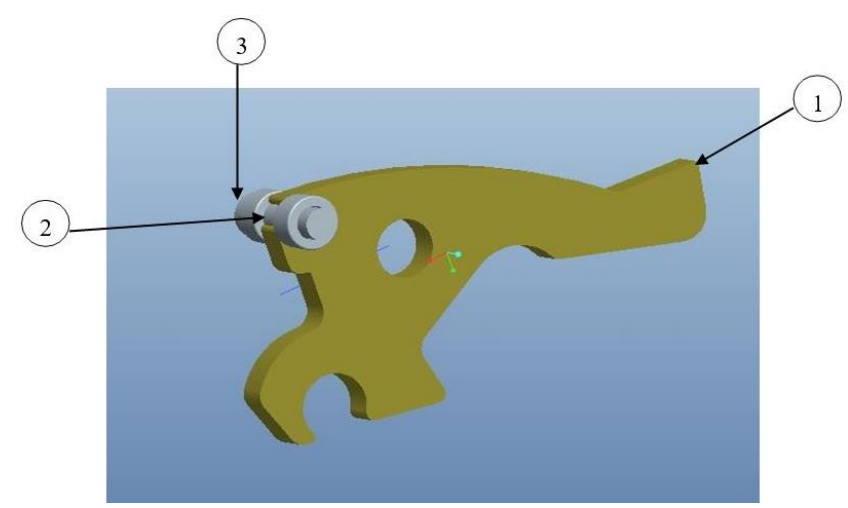

Fig.5. Proposed Latch Assembly

Figure 5 shows an alternate model of latch assembly with the following components: Latch (1), Knurling pin (2), two rollers (3) on both the sides of the pin which will be reverted from both the sides.

The rollers are provided to produce rolling between the mating part of latch and fork. This will remove the sliding contact between latch and fork and rolling contact will be coming between them. Two rollers are provided for uniform rolling. As co-efficient of rolling friction is very less compared to sliding friction, this change will be helpful in reducing the reset force.

The dimensions of the rollers and knurling pin are based on the amount of force on the unit. Also, the material is to be selected considering the amount of force on the unit.

\section{Comparison of force}

Table.1. Reset force for existing mechanism

\begin{tabular}{|l|c|}
\hline Force on knob in $\mathrm{Kg}$ & 22.76 \\
\hline $\begin{array}{l}\text { Dynamic co efficient of friction } \\
\text { with lubrication }\end{array}$ & 0.15 \\
\hline $\begin{array}{l}\text { Frictional force between fork and } \\
\text { latch }\end{array}$ & 3.4146915 \\
\hline $\begin{array}{l}\text { Total force on knob in kilograms } \\
\text { after considering sliding friction } \\
\text { betweenfork and latch }\end{array}$ & 26.18 \\
\hline
\end{tabular}

Table 1 shows the reset force for the existing mechanism and Table 2 shows the reset force for the proposed mechanism with roller assembly. As seen the reset force reduces by $3 \mathrm{kgs}$ after
Volume 02 Issue 09 September 2020 implementation of proposed assembly in the mechanism.

Table.2. Reset force for proposed mechanism

\begin{tabular}{|l|c|}
\hline Force on knob in Kg & 22.82 \\
\hline $\begin{array}{l}\text { Dynamic co efficient of friction } \\
\text { with lubrication }\end{array}$ & 0.005 \\
\hline $\begin{array}{l}\text { Frictional force between fork and } \\
\text { latch }\end{array}$ & 0.114098 \\
\hline $\begin{array}{l}\text { Total force on knob in kilograms } \\
\text { after considering rolling friction } \\
\text { betweenfork and latch }\end{array}$ & 22.93 \\
\hline
\end{tabular}

\section{Conclusion}

The new model of sub-assembly in MCCB mechanism has a roller contact between the surfaces instead of sliding contact as compared to the existing mechanism. After calculating forces between all the components using rolling friction, it is concluded that reset force is reduced by almost 3 kilograms.

\section{References}

[1] P. Clayton, R. Devanathan, Wear 156 (1992) 121-131.

[2] K.M. Kang, J.T. Song, Wear 140 (1990)119134.

[3] K.L. Johson, Contact Mechanics, Cambridge University Press, 1985 , pp. 242-255.

[4] X. Jin, P. Wu, Z. Wen, Wear 253 (2002)247256.

[5] Q.Y. Liu, X.S. Jin, Z.R. Zhou, Wear 259 (2005)439-444.

[6] M.C.Burstow, Whole Life Rail Model Application and Development for RSSBContinued Development of an RCF Damage Parameter, Rail Safety\& Standards Board, London, 2004.

[7] Houpert,L. Ball bearing and tapered roller bearing torque: analytical, numerical and experimental results. STLE Tribol Trans 2002;45(3):345-53.

[8] Houpert L. Numerical and analytical calculations in ball bearings. In: Proceedings of the 8th European space mechanism and tribology symposium. Toulouse; 1999.

[9] Mihaela Rodica D. Balan, VasileCiprianStamate, Luc Houpert, Dumitru N.Olaru., Tribology International, 
72 (2014), 1-12.

[10] Prasad.B.K , (2011) "Sliding wear behaviour of zinc- based alloy vis-à-vis gray cast iron as influenced by applied load and sliding speed", Industrial Lubrication and Tribology, Vol. 63 Iss: 3, pp.158 -170

[11] R.A. HOBBS, (1981) "ROLLING CONTACT BEARINGS", Industrial Lubrication and Tribology, Vol. 33 Iss: 3, pp. $100-105$

[12] MCB UP Ltd, (1952) "The Lubrication of BALL AND ROLLER BEARINGS: PART ONE Reasons for and Duties of the Lubricant", Industrial Lubrication and Tribology, Vol. 4 Iss: 9, pp.12-17.

[13] Regalla Srinivasa Prakash, U.R.K. Rao, A. Sethuramaiah, (2007) "Some studies on scuffing in boundary lubricated sliding contact with subsurface plastic deformation", Industrial Lubrication and Tribology, Vol. 59 Iss: 1, pp.29-37

[14] MCB UP Ltd, (1957) "Boundary Friction and Boundary Lubrication", Industrial Lubrication and Tribology, Vol. 9 Iss: 12, pp. $53-61$

[15] RyszardCzarny, (1995) "Effects of changes in grease structure on sliding friction", Industrial Lubrication and Tribology, Vol. 47 Iss: 1, pp. $3-7$ 